\title{
Paradigmatic Complementariness in Variation Studies
}

\author{
Juan Manuel Hernández-Campoy \\ Universidad de Murcia
}

\begin{abstract}
Despite the fact that linguistic change, as it is widely known, constitutes one of the great unsolved mysteries of linguistic science, and consequently a challenge to generations of linguists and philologists, we believe that the emergence of different trends in sociolinguistic research -regardless of their sophistication - and their subsequent disagreements are all evidence of the constantly increasing activity and vigour of variation studies. The importance of completing a combined approach to the phenomena of diffusion of language change from diverse perspectives, amongst which the dialectological, microsociolinguistic and geolinguistic ones must not be absent, is thus crucial. These three approaches are three different, though entirely complementary, treatments focusing on the same object of study: variation and language change phenomena. Sociolinguistics inevitably tends towards both a theoretical and methodological integration, despite the plurality existing nowadays. This integrationalist tendency has become patent in the attempts of sociolinguists to adapt themselves to those aspects and artefacts of human behaviour, such as social class, sex, age, race, ethnicity, social networks, social groups, attitudes, identity, politics, ideology, etc., as well as of human geography that affect linguistic variation and communication in general.
\end{abstract}

\section{Periodizations, scientific revolutions and metatheory}

Historical periods, or schools of thought, in the very same way as dialects, cannot be treated as discrete entities, with a monolithic nature and abrupt boundaries, since they are built upon an immediately preceding stage from which they start and against which they normally react: "Every science and every branch of study is in part a development of what went on before, and in each age the workers in any field are in part determined in the directions they take by 
the work of their predecessors, if only, in extreme cases, in the terms and principles that they deliberately reject" (Robins 1964: 314). Even, as Oyelaran (1970: 432) points out, the same phenomena are differently emphasized by different schools, and aspects, or part of one aspect of a linguistic theory may stand out as exemplified by one school and nevertheless neglected or subordinated to another aspect in the works of another school. This means, as Lass (1984: 8) suggests, that "the history of any discipline involves a lot of old wine in new bottles (as well as new wine in old bottles, new wine in new bottles, and some old wine left in the old bottles). Even ideas that seem at the moment self-evidently true do not arise out of nowhere, but are the products of a long series of trial-and-error interim solutions to perennial problems, illuminated by occasional flashes of creative insight and inspired invention. Improvements or even radical restructuring of a theory does not (or should not) imply the rejection of everything that went before". Thomas Kuhn (1962) was in fact very concerned about this nature of science in his thesis on scientific revolutions and the emergence of new paradigms.

Linguistic Theory, as Williams (1992: 40) points out, "has not emerged separately from the social philosophy of its time. Rather, it must be seen as a manifestation of the ongoing debate on the nature and the social world". In this way, while the 19th-century philologist's historicist and comparative urge was in overt opposition to the Humanism and Classicism of the Renaissance and the 17th-century Rationalism, on the other hand, the Structuralism of the beginning of the 20th century was an alternative to the 19th-century Historicism and Comparativism. Even within the same period, different theoretical trends have followed one another in Linguistics: Structuralism, Functionalism, Generativism, Variationism, etc. in the 20th century.

Idiosyncrasies of one epoch become detachable thus only when considered in perspective with those of other epochs, and it is the concentration of the different tendencies at a given moment what ultimately concedes a mnemonic value to historical periodization. Linguistic studies can not be judged, therefore, disregarding those of other periods, or even the same period, in order to contrast ontological, epistemological or axiological aspects. In this way, similarities and differences can be established between theories - and that is in fact the function of a metatheory - whereby they can be characterized, classified, and explained in terms of the criteria and relative to the conditions under which the scholar can meaningfully choose between alternative theories and/or their parts (Oyelaran 1970: 430-431).

\section{Language, society and space}

Similarly, Sociolinguistics also emerged as a kind of reaction against previous studies. Its origins, to simplify somewhat, have to be found in the context of the idiolect, the structuralist notions of langue/parole (language/speech) and diachrony/synchrony postulated by Ferdinand de Saussure, the later generativist notions of competence/performance proposed by Noam Chomsky, and the chimeric theories and unreliable methodologies of the dialectological tradition. Langue was related to the linguistique interne, or MICROLINGUISTICS, which is concerned solely with the structure of language systems and works with phonology, morphology, syntax and semantics as common levels of analysis. 
Parole was related to the linguistique externe, or MACROLINGUISTICS, which is concerned with language in a broad sense: it involves the acquisition and use of language, the interdependence of culture, society and language, the mechanisms involved in languagebehaviour, and so on (Lyons 1981: 36).

The Saussurean systematic homogeneity of langue, on the one hand, is concerned with Chomskyan competence, focused on the "ideal speaker-listener in a completely homogeneous speech-community, whoknows its language perfectly ..." (Chomsky 1965:3), and Saussurean parole, on the other hand, is concerned with Chomskyan performance, focused on the concrete utterances produced by individual speakers in real situations irrespective of the abstract rule system. Languages were seen as coherent, autonomous, and self-sufficient systems, and linguists were only interested in the formal features of an idealized langue (Stern 1983: 218). In other words, in the past, linguists concentrated on MICROLINGUISTICS, the systematic homogeneity of langue and the speaker's competence, deliberately ignoring the MACROLINGUISTIC level with the orderly heterogeneous parole and the speaker's performance, and appealing to the Bloomfieldian notion of free variation as an explanation of any kind of linguistic variability: "Everyone knows language is variable', said Edward Sapir in 1925. However, through the history of linguistics, linguists have tended to act as if language were not variable. Most linguistic theories have started from the assumption that variability in language is unmanageable, or uninteresting, or both. Consequently, there has been a tendency to abstract away from the variable data that linguists inevitably encounter in order to begin the analysis at some more homogeneous 'level"' (Chambers and Trudgill 1980: 145). The fact that "most if not all speech communities are more or less socially and linguistically heterogeneous" is a complexity which makes things much more difficult to any linguist wishing to describe a particular variety (Trudgill 1983a: 37). Therefore, for many years the reaction of linguists to this complexity was generally to ignore it by concentrating their studies either on the idiolect or on the speech of rural informants, particularly that of elderly people of little education and little travelling experience, in small isolated villages, with the obsession of looking for the 'real' or 'pure' dialects. But, obviously, the idiolect, "the speech of one person at one time in one style", was not precisely more regular than the speech of the community as a whole, and the 'real' or 'pure' homogeneous dialect turned out to be a chimera. A monolithic linguistic system was unable to explain the real fact that the social structure could maintain any causal relation with that variability present in language (LópezMorales 1989:21). There was an obvious reaction against this theoretical model of language that resulted in a shift from the fictional notion of systematically homogeneous to the orderly heterogeneous speech community. In HernándezCampoy (1993: 19) the origins of sociolinguistic studies are simplified in the following chart:

After the Second World War traditional dialectologists realized that in confining dialect studies to rural areas they were ignoring the speech of the vast majority of the population, i.e., the speech of large urban areas, which could not be investigated by applying the methods of traditional rural dialectology. And it was mainly from the sixties that, with the collaboration of social scientists and on the assumption of the heterogeneous nature of linguistic communities, some linguists became interested in MACROLINGUISTICS (i.e., linguistique externe), undertaking the complex reality of language in use in society with the help of the 


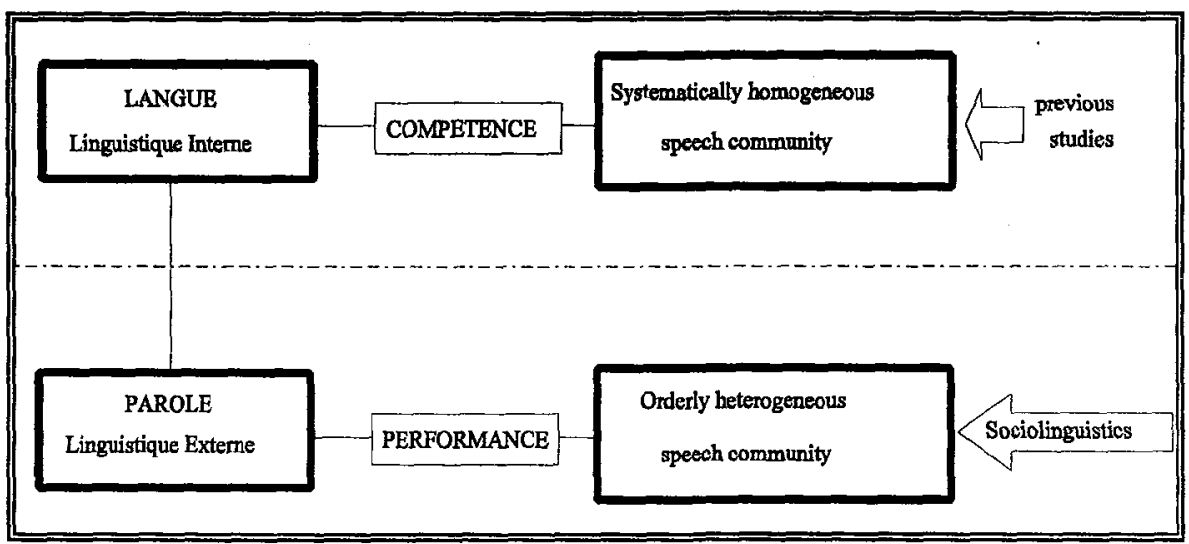

Source: Hernández-Campoy (1993: 19)

microlinguistic levels of analysis as linguistic variables. In this way, Urban Dialectology appeared conveying both a linguistic and a social function. This evolution, both theoretically and methodologically, from Traditional Rural Dialectology to Modern Urban Dialectology, and, as we will see later, thence to modern Geolinguistics, is as evident as it is natural.

The consideration of the study of language variation as carried out through three different cardinal reference dimensions (time, space, and society) leads to the broad conclusion that Traditional Dialectology has been predominantly concerned with time and geography(static space), Labovian Sociolinguistics is predominantly focused on society, andGeolinguistics on geography (dynamic space).

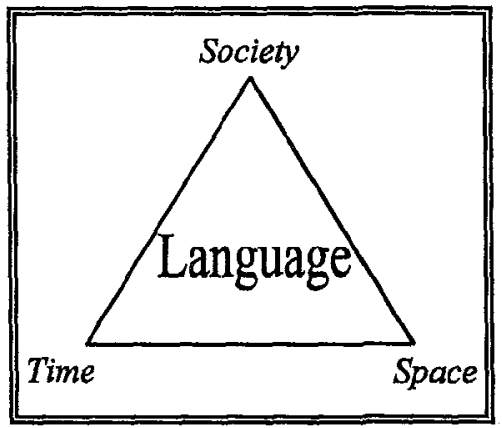

While TraditionalDialectology has so far been mostly interested in language variation geographically and diachronically (processes that have already taken place), Labovian Sociolinguistics, on the other hand, is also concerned with language variation but synchronically and in the social context (processes still taking place). Winthrop Nelson Francis (1983: 150) describes Traditional Dialectology as 'item-centred', in the sense that its "interest is focused on individual facts of the variable distribution of a single sound without attempting to relate them to the overall structure of the dialects involved", whereas 
Labovian Sociolinguistics can be described as 'speaker-centred', since its interest is focused on the speaker's competence and performance.

If dialectologists selected elderly rural informants in order to avoid the problems at the stylistic level and Labov's observer's paradox, sociolinguists, or 'real-world' linguists, on the other hand, tend to be very concerned with the problems of the influence of the interviewer and the tape-recorder, and thus with the difficulty of obtaining casual speech, the vernacular. In fact, while both disciplines are interested in vernacular speech, their motivations are different, since Traditional Dialectology has regarded the vernacular as the variety least influenced by the standard, the site of the 'pure' or 'real' homogeneous dialect, whereas Sociolinguistics considers it as systematic, regular and the site of ongoing changes (Trudgill 1983b: 42).

Yet, from the point of view of Geolinguistics, the concepts of space and spatiality, or the spatial properties, and their necessary integration within sociolinguistic theory, as Britain (1991) underlines, have until recently performed a marginal role in the evolution of linguistic thought. Time and historical developments constituted the models of analysis in Historical Linguistics, with its wave theory, and in Comparative Philology, with its family-tree theory, as these eminently diachronic studies can show us. Nor in this ambit of historical and comparative linguistics was Traditional Dialectology removed from historicist tendencies, despite being concerned with the study of the variability present in language from a geographical perspective. The difference in its treatment lies in its approach, which largely coincided with that used by Human Geography by the 1960s and which focused on regions, or dialects, having 'place', 'difference' and 'distinctiveness' as the most prominent features of its analysis: "rather than focusing on spatial processes or structures, individual areas were analysed for individual unique characteristics, totally independently of their neighbours" (Britain 1991: 202). In this way, dialectologists, stimulated by the Neogrammarian Hypothesis and assuming that dialects were homogeneous and discrete entities separated by dialect boundaries, devoted themselves to drawing isoglosses - their principal theoretical construct - on linguistic maps with the aim of 'dissecting' and displaying the discreteness of dialect areas. However, traditional dialectologists neither took into account a social dimension nor put more emphasis on space except by considering it as a mere container of linguistic variation: they reduced their work to the visual display on maps of the geographical distribution of phonetic-phonological, morpho-syntactic or lexical-semantic variation. Their perception of space was, therefore, rather static. In confining themselves to considering only time and historicity with the aim of reconstructing the dialect variation existing in the past or present of a given language, they ignored society's dynamism and did not assess the possible interrelationship between different locations.

Sociolinguistics carries out its studies on language change from a social dimension surveying the social space (the vertical axis) determined by the social classes of an individual urban centre and considering its possible relationship with linguistic variation. But, according to geolinguists, sociolinguists have never paid attention to physical space (the horizontal axis) and its possible relationship with the behaviour of other urban nuclei. Since research in urban centres has come to be considered as the most adequate means of gaining access to the most fluid and heterogeneous communities, sociolinguists take an interest in 
urbanism and its specificity (Soja 1989: 69). If, as Soja (1989: 12) asserts, society is the result of the confluence of time, space and social being, space and spatiality should play a more relevant role in the development of sociolinguistic research for evidencing the interrelationships between language, society and geography.

While Traditional Dialectology was eminently rural and Labovian Sociolinguistics (Urban Dialectology) is eminently urban, Geolinguistics is a multidisciplinary sociolinguistic branch interested in the spatial characteristics of language and whose nature is based, as its mentors Chambers and Trudgill (1980) conceive it, on the confluence of three areas: linguistic geography (Dialectology), urban dialectology (Sociolinguistics) and human geography (Geography). Geolinguistics is thus concerned with the relationships between language and geography: the spatial study of language, or the study of language in its geographical context, in addition to the social and cultural contexts; as Chambers (1982:1) puts it, the study of "the geographical dispersions of linguistic elements". With their rigorous adoption of scientific methods, the geolinguists' explicit positivist desire is to develop a quantified geographical perspective where spatial factors are capable of explaining entirely the establishment of laws, spatial relationships and spatial processes. These aims of explanation and prediction make these scholars focus on researching not what phenomena happen and where, which would solely be descriptive in intent, but the reasons why they occur where they do instead of arising in other places, which is clearly explanatory and predictive in intent (see Hernández-Campoy 1996). Likewise, in order to express accurately and plainly the results of their analysis, they demand from themselves the use of the language of mathematics and logic, verifiability being the fundamental criterion and coincidence being conceived in terms of probability (Capel Sáez 1981).

If considering who talks to whom, when, how, and with what purpose is an important postulate in sociolinguistic research, in the same way, considering where that action is done from a macro-level, where a linguistic community is physically located and its possible interaction as well as its inter-relationship with others in different urban centres is of great relevance for geolinguistic studies. It combines, therefore, as Britain (1991: 10-11) points out, the enormous number of data accumulated by traditional dialectologists, the methodological rigour of Labov's Secular Linguistics and a more profound understanding of spatial networks and the diffusion of sociolinguistic innovations. Therefore, in the same way as the linguistic variable, with the help of sociological theory and methods, can improve our knowledge of the relationship between language and society, "the linguistic variable, together with a number of methodological and theoretical insights from human geography, can improve our knowledge of the relationship between language and geography, and of the geographical setting of linguistic change" (Trudgill 1983b: 52): "A dynamic dialectology or geolinguistics making use of time-incorporating geographical diffusion models and sociolinguistic and geographical techniques that permit the handling of gradient phenomena, may be better able to describe and even explain some of the processes involved in the geographical diffusion of linguistic innovations" (Trudgill 1983b: 87).

Similarities and dissimilarities between this kind of Geolinguistics and Traditional Dialectology are undoubtedly appreciable. Dialectologists themselves never considered their field of study as a social science nor even adopted its theoretical or methodological principles 
until William Labov appeared with modern Urban Dialectology. The traditional spatial dimension had a completely static nature, with importance being attached to the results of processes rather than to the processes themselves (Trudgill 1983b: 87), as it was confined to the cartographic representation of the geographical distribution of linguistic forms. Traditional dialectologists gave no explanation at all of the geographic distribution of linguistic phenomena, that is, "why a certain linguistic variety occurred in some part of the country and not in another" (Gerritsen 1988: 1575). In fact, scholars such as Bailey (1973) consistently thought that geography is an irrelevant factor in the contact and diffusion processes and linguistic phenomena: "Geographical dispersions can be so chaotic as to challenge the plausibility of any hypotheses about the orderliness of language variation" (Bailey 1973: 86). Chambers' answer to this statement is as sufficiently straightforward as it is clarifying: "Even prima facie, it is simply inconceivable that language, as a human property, would not reflect the spatial relationships which bring human beings together and keep them apart. True, the reflection of language in geography may not be as simple as Bailey and others apparently expected, but that is surely no reason dismiss it altogether. What is required is a richer set of hypotheses about language variation and a more profound understanding of spatial networks and diffusion patterns" (Chambers 1982: 2). Geolinguistics, from the outset, is completely aware of the shortcomings of the "traditional way' and provides us with a more dynamic dimension, where spatial inter-relationships of linguistic features are of great importance: "Instead of giving up on the relationship between linguistic orderliness and geographical dispersion, what is required is a richer set of hypotheses about language variation and a more profound understanding of spatial networks and the diffusion of innovations" (Chambers and Trudgill 1980: 206).

Likewise, similarities and dissimilarities between Geolinguistics and Sociolinguistics are also evident. Basically, there are no differences inasmuch as the former belongs to the overall paradigm of the latter. In Britain's opinion, both perspectives necessarily complement each other: "It is impossible, I will claim, to conceive not only of a geolinguistics without a social content, but also that it is theoretically incorrect to investigate the social phenomena of language devoid of a consideration for the spatial" (Britain 1991: 11). The difference between them lies in the treatment of spatiality, since, while Geolinguistics focuses on space, Labovian Sociolinguistics focuses on society: "the former asocially quantifies'space, whereas the latter aspatially quantifies society" (Britain 1991: 209).

The foundations of Geolinguistics and its subsequent development, are, consequently, clearly and inevitably dialectological as well as sociolinguistic. In fact, Chambers (1993) has called it 'sociolinguistic dialectology', and, similarly, Trudgill (1.983b: 51) has labelled it as 'sociolinguistically informed dialectology' and has always defended its integrity from the point of view of the rigour and accuracy required by empiricist research: "I therefore want to propose that it may be possible to effect an improvement in our descriptions of geographical dialects - and hence in our ability to explain dialect phenomena-by adopting a geographical and sociolinguistic-influenced methodology [...]. If such a methodology proves to be successful, then explanations may follow" (Trudgill 1983b: 54).

Given these considerations, the completion of a combined approach to the phenomena of diffusion of language change from diverse perspectives, amongst which the 
dialectological, micro-sociolinguistic and geolinguistic ones must not be absent, is not only desirable also necessary. These three approaches are three different, though, as Trudgill (1992a) maintains, entirely complementary and interrelated, treatments focusing on the same object of study: variation and language change phenomena. The approaches developed by traditional dialectological and geolinguistic research are proposed to study the linguistic behaviour of social groups at a macro-level of interaction (macro-sociolinguistics), while the approaches developed in micro-sociolinguistic research aim to study individuals' linguistic behaviour at a micro-level of interaction (see Hernández-Campoy 1996).

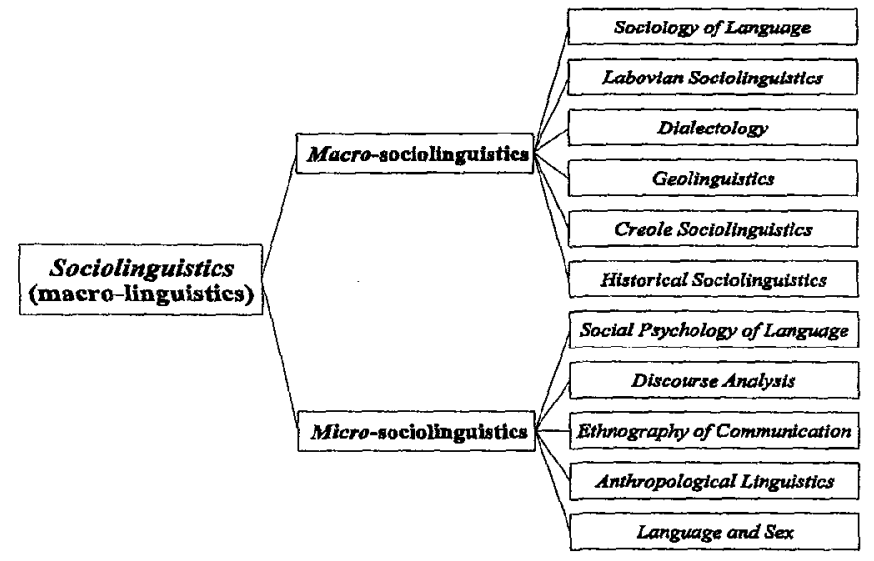

We know that, with their descriptive cartographic reproductions of 'pure' dialect differences, traditional dialectologists have frequently been considered as 'mere butterfly collectors' and even practicioners of 'a kind of linguistic archaeology', above all because of the imbalance between theoretical assumptions, object of study and motivations, methods, and techniques employed. But it is also true, as Trudgill (1992a: 72) acknowledges, that their studies of geographically varying linguistic forms in rural areas were of considerable value, since with these surveys important and interesting linguistic data were recorded before disappearing forever; and what is more, those data would not have been able to be used in subsequent analysis, such as the sociolinguistic studies carried out in Martha's Vineyard and New York City (Labov 1966), Norwich (Trudgill 1971, 1974a), Montreal (Sankoff and Cedergren 1971), Belfast (Milroy and Milroy 1978), Glasgow (Macaulay 1977, 1978), Reading (Cheshire 1978, 1982), San Juan (López Morales 1983), Sydney (Horvath 1985), East Anglia (Britain 1991), Milton Keynes (Kerswill and Williams 1994), etc.

Both the integrationalist tendency proposed and the interdiciplinary perspective used by Sociolinguistics from the 1960s have become patent in the attempts of (socio)linguists to take into consideration those aspects of human behaviour, such as social class, sex, age, race, ethnicity, social networks, social groups, attitudes, identity, politics, ideology, etc., and of human geography that affect linguistic variation through the insightful expertise taken from other sciences, such as Sociology, Anthropology, Psychology or Human Geography. Milroy and Milroy's (1985) social networks and the speaker's degree of adherence to them (his/her 
core/peripheral nature) affect very considerably the possibility of adoption, and subsequent diffusion, or rejection of innovations: the weaker the uniplex social networks and the higher the degrees of contact with similar speakers of other different varieties individuals of a particular community have, the more innovative their language variety is; while, conversely, the stronger the multiplex social networks and the lower the degrees of contact with similar speakers of other different varieties individuals of a particular community have, the more conservative their language variety is. Giles' (1973, and Giles and Smith 1979) linguistic accommodation to salient linguistic features of other accents/dialects in face-to-face interaction is also crucial in the geographical diffusion of linguistic innovations. In fact, "diffusion can be said to have taken place, presumably, on the first occasion when a speaker employs a new feature in the absence of speakers of the variety originally containing this feature" (Trudgill 1986: 40). Regular mobility leads inevitably to the weakening of ties to local communities, those speakers whose social contacts are class-heterogeneous being more likely to act as potential innovators. Both the social and spatial mobility of speakers generates a greater exposure to linguistic accommodation phenomena, and, consequently, to the transmission of innovations.

The models of analysis of diffusion developed in Geolinguistics also have both advantages and disadvantages. According to Gerritsen (1988: 1589), "the most important advantage of the use of human geographical models for dialect geographical purposes is that it prevents giving ad hoc explanations", since it requires from the researcher the determination of $i$ ) the factors causing a diffusion, and $i i$ ) the presence of those factors in the diffusion area and not where the phenomenon did not spread. According to Hard (1972: 58), these simulation models are useful for verifying hypotheses about the causes of a diffusion process, accepting or rejecting them, since they can at best show that a given explanation is or is not highly probable. For their part, Trudgill (1974b) and Chambers and Trudgill (1980) go further and make a greater defence of the models: not only are they considered useful in that they allow the researcher to verify or invalidate hypotheses about the origins of a diffusion, but also they have a heuristic value, since, in cases where the model does not work, the researcher necessarily has to find out the reasons and explain them. It could be true that these probabilistic models of macroscopic analysis are characterized by a deterministic approach, involving a specification of the relationship between diffusion and its explanatory variables, and that they are specifically designed for predicting diffusion flows but only under restricted assumptions, as Jones (1990: 199) states in the case of probabilistic models for migration. But, there is no room for doubt, and we fully agree with Gerritsen (1988: 1589), that regardless of their precise evidencing and explanatory power, the geolinguistic approach to linguistic diffusion processes developed with models adapted from Human Geography is considerably more well-founded than that of traditional dialectologists. Obviously, this supplementary evidencing and explanatory value has a price to pay, which is its inconveniences: $i$ ) the need to collect and work with data unfamiliar to linguists, such as population sizes, distances, communications, (air, land and sea) connections, physical geographical aspects, etc.; ii) quantification of data; and iii) the division of the landscape into areas of uniform size and shape; in addition to $i v$ ) the obtainment of linguistic, social and geographical data for each cell in question. 


\begin{tabular}{|c|c|c|c|}
\hline concepts & $\begin{array}{c}\text { TRADITTONAL } \\
\text { DIALECTOLOGY }\end{array}$ & SOCIOLINGUISTICS & GEOLINGUISTICS \\
\hline time & $\checkmark$ & $\checkmark$ & $\checkmark$ \\
\hline space \& spatiality & $\checkmark$ (static space) & & $\checkmark$ (dynamic space) \\
\hline society & & $\checkmark$ & $\checkmark$ \\
\hline \multicolumn{4}{|l|}{ langue } \\
\hline parole & $\checkmark$ & $\checkmark$ & $\checkmark$ \\
\hline competence & & $\checkmark$ & $\checkmark$ \\
\hline performance & $\checkmark$ & $\checkmark$ & $\checkmark$ \\
\hline idiolect & $\checkmark$ & & \\
\hline sociolect & & $\checkmark$ & $\sim$ \\
\hline geolect & & & $\checkmark$ \\
\hline $\begin{array}{l}\text { speech } \\
\text { community }\end{array}$ & $\begin{array}{l}\text { systematically } \\
\text { homogeneous }\end{array}$ & $\begin{array}{c}\text { orderly } \\
\text { heterogeneous }\end{array}$ & $\begin{array}{c}\text { orderly } \\
\text { heterogeneous }\end{array}$ \\
\hline $\begin{array}{l}\text { variation \& } \\
\text { change }\end{array}$ & $\checkmark$ & $\checkmark$ & $\checkmark$ \\
\hline vernacular & $\checkmark$ (pure dialect) & $\checkmark$ (site of variation) & $\checkmark$ \\
\hline dialects & discrete entities & dialect continuum & dialect continuum \\
\hline diffusion & $\begin{array}{l}\text { (geographical: } \\
\text { wave theory, } \\
\text { epidemic) }\end{array}$ & $\checkmark$ (social) & $\begin{array}{l}\checkmark \text { (geographical: } \\
\text { gravity models, } \\
\text { hierarchical) }\end{array}$ \\
\hline $\begin{array}{l}\text { social interaction } \\
\text { and networks }\end{array}$ & & $\checkmark$ & $\checkmark$ \\
\hline $\begin{array}{l}\text { spatial interaction } \\
\text { and networks }\end{array}$ & & & $\checkmark$ \\
\hline ruralareas & $\checkmark$ & & \\
\hline urban areas & & $\checkmark$ & $\checkmark$ \\
\hline processes & & $\checkmark$ & $\checkmark$ \\
\hline results & $\checkmark$ & $\checkmark$ & $\checkmark$ \\
\hline $\begin{array}{l}\text { empirically-based } \\
\text { methodology }\end{array}$ & & $\checkmark$ & $\checkmark$ \\
\hline description & $\checkmark$ & $\checkmark$ & $\checkmark$ \\
\hline prediction & & $\checkmark$ & $\checkmark$ \\
\hline $\begin{array}{l}\text { observer's } \\
\text { paradox }\end{array}$ & & $\checkmark$ & $\checkmark$ \\
\hline variable & & $\checkmark$ & $\checkmark$ \\
\hline statistical aid & & $\checkmark$ & $\checkmark$ \\
\hline
\end{tabular}


Although the geolinguistic gravity models often give adequate statistical explanation for the volume, distance and direction of diffusion flows by submitting aggregate data to macroscopic analysis, i.e. in their search for empirical regularities in aggregate data, however, they do not manage to reveal to us anything about face-to-face interaction between the speakers of the urban centres in question nor about the reasons leading them to adopt or reject an innovation. An approach to these diffusion phenomena from the microsociolinguistic level of interaction (social network theory) is thus also necessary, since there are attitudinal factors that may stimulate or retard the adoption of innovations and its subsequent transmission. The arbitrary and subjective nature of social attitudes towards the prestige of dialect varieties is largely responsible for the origination of changes in linguistic systems.

In any case, we must admit that linguistic change, as Trudgill (1992b: vii) asserts, "constitutes one of the great unsolved mysteries of linguistic science, and the puzzle of the causation and function of language change is a challenge that generations of linguists and philologists have wrestled with [...]". We believe, in the same way as many other scholars (see Chambers and Trudgill 1980, Walters 1988, Trudgill 1992a, etc) advocate, that the emergence of different trends and schools, regardless of their sophistication and their subsequent disagreements, are all evidence of the constantly increasing activity, vigour and thus development of variation studies: from the wave-theory of Historical Linguistics, the family-tree theory of Comparative Philology, the different surveys of dialects of Traditional Dialectology, the social dialect, social network and accommodation theories of Sociolinguistics to the gravity models of Geolinguistics.

\section{Conclusion}

Sociolinguistics, as a paradigm, inevitably tends towards boty a theoretical and methodological integration, despite the plurality existing nowadays and despite Fishman's opinion: "After three decades, sociolinguistics has remained just as it was: a province of linguistics and anthropology, and a rather provincial province at that" (Fishman 1991: 132). In fact, Sociolinguistics emerged with the single as well as crucial assumption of the social nature of language: the structuralist notion of 'free variation' was discredited and considered to be a fallacy by demonstrating that variation is not precisely free but rather socially and/or contextually conditioned ('sociolinguistic variation'). Since then, Sociolinguistics has been consolidating all its foundations, fortunately -in our opinion- thanks to the interdisciplinarity practised so far: sociology and linguistics (Sociolinguistics, the Sociology of Language), psychology and linguistics (the Social Psychology of Language), anthropology and linguistics (Anthropological Linguistics), ethnography and linguistics (the Ethnography of Communication), geography and linguistics (Geolinguistics), etc. (see Hernández-Campoy 1993). Furthermore, we consider that, when it comes to reaching agreement within the spectrum of language and society, it would be desirable to redefine both the ideology and metatheory of linguistic studies in sociolinguistic terms, or, being even more ambitious, in a multidimensional space of the sphere of language and social communication. This 
integration, based on paradigmatic complementariness, old wine and new wine, would provide us with a greater refinement and precision in analysis, as well as signifying a step forward in the development of our understanding of language change and diffusion. It will in turn contribute, therefore, to the location of language in and through time, social and geographical space, and, finally, constitute points of convergence in the improvement of linguistic theory, and, ultimately, of our understanding of its nature and structure as a human faculty.

In conclusion, and quoting R.H. Robins (1964:319), "[d]uring these men's lifetimes and through their work we have witnessed striking and encouraging growth, both in the subject itself and in the scholarly interest taken in it. Much remains to be accomplished; new lines of thought open up, and new methods must be devised to follow them; and general linguistic theory must be always keeping pace with methodological progress. The languages of mankind in all their fascinating detail and with all their inmense power among the human faculties still present a potentially limitless field for disciplined investigation and systematic study. It is altogether right that they should be the object of scholarly enthusiasm, controlled imagination, and great reverence".

\section{Works cited}

Ammon, U., N. Dittmar and K.J. Mattheier, eds. Sociolinguistics: An International Handbook of the Science of Language and Society. Vol 2. Berlin: Walter de Gruyter, 1988.

Bailey, C.J. Variation and Linguistic Theory. Arlington: Center for Applied Linguistics, 1973.

Bolton, K. and H. Kwok, eds. Sociolinguistics Today: International Perspectives. London: RKP, 1992.

Britain, D. Dialect and Space: A Geolinguistic Analisis of Speech Variables in the Fens. Unpublished Ph.D. Thesis. Colchester: University of Essex, 1991.

Capel Sáez, H. Filosofía y ciencia en la geografía contemporánea: una introducción a la geografía. Barcelona: Barcanova, 1981.

Chambers, J.K. "Geolinguistics of a Variable Rule". Discussion Papers in Geolinguistics, 5(1982): $1-17$.

"Sociolinguistic Dialectology". In Preston, ed., 1993. and P.J. Trudgill. Dialectology. Cambridge: CUP, 1980.

Chomsky, N. Aspects of the Theory of Syntax. Cambridge, Mass.: MIT Press, 1965.

Cheshire, J. "Present Tensc Verbs in Reading English". In Trudgill, ed., 1978. Variation in an English Dialect. Cambridge: CUP, 1982.

Darnell, R., ed. Linguistic Diversity in Canadian Society. Champaign, Ill.: Linguistic Research, Inc, 1971.

Ennen, E. and G. Wiegelmann, eds. Festschrift Matthias Zender, Studien zur Volkskultur, Sprache und Landesgeschichte. Bonn, 1972.

Fishman, J.A. "Putting the 'Socio' Back into the Sociolinguistic Enterprise" (Special article). International Journal of the Sociology of Language 92 (1991): 127-138.

Francis, W.N. Dialectology: An Introduction. New York: Longman, 1983.

Gerritsen, M. "Sociolinguistic Developments as a Diffusion Process". In Ammon, Dittmar and Matheier, eds., 1988: 1574-1591. 
Giles, H. (1973). "Accent Mobility: A Model and Some Data". Anthropological Linguistics, 15 (1973): 87-105.

Giles, H. and P. Smith. "Accommodation theory: Optimal Levels of Convergence". Language and Social Psychology (Language in Society Series). Eds. H. Giles and R. St. Clair Oxford: Basil Blackwell, 1979.

Hard, G. "Ein geographisches Simulations-modell für die rheinische Sprachgeschichte". In Ennen and Wiegelmann, eds., 1972: 25-59.

Hernández-Campoy, J.M. Sociolinguiistica británica: introducción a la obra de Peter Trudgill (Serie Universidad Lingüística). Barcelona: Ediciones Octaedro, 1993.

Modelos de difusión geográfica de las innovaciones sociolingüísticas en los acentos del Reino Unido. Murcia: Universidad de Murcia, 1996.

Horvath, B. Variation in Australian English: The Sociolects of Sydney. Cambridge: CUP, 1985.

Jones, H. Population Geography. London: PCP, 1990.

Kerswill, P.E. and A. Williams. A New Dialect in a New City: Children's and Adults' Speech in Milton Keynes. Final report and summary of research submitted to the Economic and Social Resource Council, Rf. R000232376. London: ESRC, 1994.

Kuhn, T.S. The Structure of Scientific Revolutions. Chicago: The University of Chicago Press, 1962. Labov, W. The Social Stratification of English in New York City. Washington, D.C.: Center for Applied Linguistics, 1966

Lass, R. Phonology. Cambridge: CUP, 1984

López Morales, H. Estratificación social del español de San Juan de Puerto Rico. Mexico: Universidad Nacional Autónoma de México, 1983.

La sociolinguíistica. Madrid: Gredos, 1989.

Lyons, J. Language and Linguistics: An Introduction. Cambridge: CUP, 1981.

Macaulay, R. Language, Social Class, and Education: A Glasgow Study. Edinburgh: Edinburgh University Press, 1977.

"Variation and Consistency in Glaswegian English". In Trudgill, ed., 1978.

Milroy, J. Linguistic Variation and Change. (Language in Society Series, 19). Oxford: Blackwell, 1992.

1978.

and L. Milroy. "Belfast: Change and Variation in an Urban Vernacular". In Trudgill, ed.,

Newmeyer, F.J., ed. Linguistics: The Cambridge Survey. 4 vols. Cambridge: CUP, 1988.

Oyelaran, O.O. "Aspects of Linguistic Theory in Firthian Linguistics". Word 23 (1970): 428-52.

Preston, D., ed. American Dialect Research. Philadelphia, PA: John Benjamins, 1993.

Robins, R.H. General Linguistics. An Introductory Survey.London: Longman, 1964. (3rded. 1980)

Sankoff, G. and H. Cedergren. "Some Results of a Sociolinguistic Study of Montreal French". In Darnell, ed., 1971.

Soja, E. Postmodern Geographies: the Reassertion of Space in Critical Social Theory. London: Verso, 1989.

Stern, H.H. Fundamental Concepts of Language Teaching. Oxford: OUP, 1983.

Trudgill, P.J. The Social Differentiation of English in Norwich. Unpublished Ph.D. Thesis. Edinburgh: University of Edinburgh, 1971.

The Social Differentiation of English in Norwich. Cambridge: CUP, 1974a.

."Linguistic Change and Difussion: Description and Explanation in Sociolinguistic

Dialect Geography". Language in Society 3 (1974): 215-246. , ed. Sociolinguistic Patterns in British English. London: Edward Arnold, 1978. 
Sociolinguistics: An Introduction to Language and Society. Revised ed. London: Penguin, 1983a. (1st ed. 1974) . On Dialect: Social and Geographical Perspectives. Oxford: Blackwell, $1983 \mathrm{~b}$. (1992a). . "Dialect Contact, Dialectology and Sociolinguistics". In Boiton and Kwok, eds., 1992, ."Editor's Preface". In Milroy, 1992, (1992b).

Walters, K. "Dialectology". In Newmeyer, ed., 1988: 119-139 (vol. IV).

Williams, G. Sociolinguistics: A Sociological Critique. London: Routledgc, 1992. 